\title{
A joint Cluster and ground-based instruments study of two magnetospheric substorm events on 1 September 2002
}

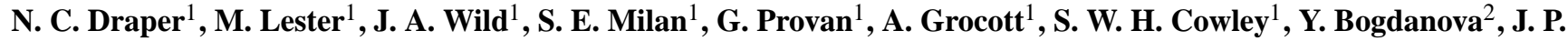 \\ Dewhurst $^{2}$, A. N. Fazakerley ${ }^{2}$, J. A. Davies ${ }^{3}$, and J.-M. Bosqued ${ }^{4}$ \\ ${ }^{1}$ Radio and Space Plasma Physics Group, Department of Physics and Astronomy, University of Leicester, Leicester LE1 \\ 7RH, UK \\ ${ }^{2}$ Mullard Space Science Laboratory, Holmbury St Mary, Dorking, Surrey RH5 6NT, UK \\ ${ }^{3}$ Space Science and Technology Department, Rutherford Appleton Laboratory, Chilton, Didcot, Oxon OX11 0QX, UK \\ ${ }^{4}$ CESR/CNRS, BP 4346 9, Avenue Colonel Roche, 31028 Toulouse CEDEX 4, France
}

Received: 19 March 2004 - Revised: 27 July 2004 - Accepted: 15 September 2004 - Published: 22 December 2004

\begin{abstract}
We present a coordinated ground- and spacebased multi-instrument study of two magnetospheric substorm events that occurred on 1 September 2002, during the interval from 18:00 UT to 24:00 UT. Data from the Cluster and Polar spacecraft are considered in combination with ground-based magnetometer and HF radar data. During the first substorm event the Cluster spacecraft, which were in the Northern Hemisphere lobe, are to the west of the main region affected by the expansion phase. Nevertheless, substorm signatures are seen by Cluster at 18:25 UT (just after the expansion phase onset as seen on the ground at 18:23 UT), despite the $\sim 5 \mathrm{R}_{E}$ distance of the spacecraft from the plasma sheet. The Cluster spacecraft then encounter an earthwardmoving diamagnetic cavity at 19:10 UT, having just entered the plasma sheet boundary layer. The second substorm expansion phase is preceded by pseudobreakups at 22:40 and 22:56 UT, at which time thinning of the near-Earth, $\mathrm{L}=6.6$, plasma sheet occurs. The expansion phase onset at 23:05 UT is seen simultaneously in the ground magnetic field, in the magnetotail and at Polar's near-Earth position. The response in the ionospheric flows occurs one minute later. The second substorm better fits the near-Earth neutral line model for substorm onset than the cross-field current instability model.
\end{abstract}

Key words. Magnetospheric physics (Magnetosphereionosphere interactions; Magnetic reconnection; Auroral phenomenon)

\section{Introduction}

Substorm onset models have broadly developed into two categories, the near-Earth neutral line (NENL) model and the

Correspondence to: N. C. Draper

(ncd8@ion.le.ac.uk) cross-field current instability (CCI) model. Each consists of three phases; the growth phase (McPherron, 1970), the expansion phase and the recovery phase (Akasofu, 1964).

The NENL model (Baker et al., 1996 and references therein) considers the magnetotail loading that occurs during the growth phase to be a process that cannot be indefinitely continued; if it were, either the plasma sheet would thin until its scale was that of an ion gyroradius, or the dayside magnetopause would be completely eroded through reconnection. As neither of these occur, a NENL forms due to spontaneous reconnection in the central plasma sheet at a distance downtail of around 20 to $30 \mathrm{R}_{E}$ from Earth (as suggested by the magnetic reconnection study by Nagai et al., 1998). Initially, the closed magnetic field lines threading the nightside plasma sheet are reconnected, followed by reconnection of the open field lines which form the lobes of the tail. Magnetic field lines closed during this time are subsequently returned to the dayside. The NENL formation decreases the current in that region of the central plasma sheet. This disturbs the current flow, which must be diverted away from this area, either earthward, enhancing the inner current sheet, or tailward, leading to plasmoid formation, or it is redirected along magnetic fields that are connected to the ionosphere, creating the substorm current wedge (SCW; McPherron et al., 1973). Therefore, in the NENL model, substorms are initiated by the spontaneous formation of a magnetic reconnection line in the near-Earth tail, with current disruption in the inner current sheet occurring as a result.

A modified NENL model has also been proposed by Shiokawa et al. (1998), in which high-speed earthward ion flow in the current sheet (earthward of the near-Earth neutral line, which is formed first) is braked in the region where a tail-like field becomes dipolar, resulting in a dawnward inertia current at the boundary between the two types of fields. This boundary gradually moves tailward after expansion phase onset as a result of flux pile-up in the region. 


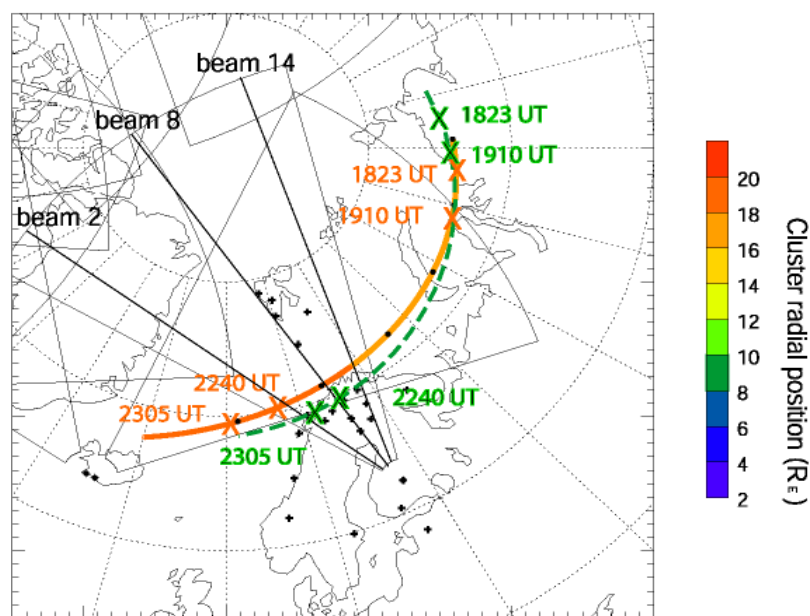

Fig. 1. Cluster 1 (Rumba) footprint (solid orange line) and Polar footprint (dashed green line) mapped on to SuperDARN fields-ofview, with IMAGE magnetometer stations (black crosses). Times of interest are marked with orange crosses for the Cluster footprint and green crosses for the Polar footprint.

In this picture the substorm current wedge is formed at this braking point. The CCI model (Lui (1996) and references therein) considers the high level of magnetic field fluctuations in the near-Earth current sheet at the start of the expansion phase (substorm onset). These are attributed, in this model, to the current disruption and turbulence in the magnetic field. Current disruption causes the formation of the SCW, diverting current flow to the ionosphere. The NENL is formed as a result, allowing reconnection and plasmoid formation further downtail from the SCW region. The nearEarth current sheet disruption can initiate a rarefaction wave which is propagated downtail (Chao et al., 1977). This leads to the thinning of the plasma sheet and tail reconnection. Therefore, in the CCI model, the substorm onset is initiated at the inner edge of the current sheet and subsequently propagates both earthward via the SCW and downtail to form the NENL.

In this paper we present observations in the tail and ionosphere from an interval in which two substorm expansion phases occur. From these observations we discuss the relative merits of the two substorm onset models described above.

\section{Instruments}

Figure 1 presents the position of the footprints of the Cluster 1 (Rumba, solid orange line) and Polar spacecraft (dashed green line) in a geographic coordinate system on 1 September 2002 between 18:00 and 24:00 UT. Also indicated are the fields of view of some of the Northern Hemisphere SuperDARN radars (Greenwald et al., 1995) with beams 2, 8 and 14 marked for the Hankasalmi (Finland) radar. The locations of IMAGE ground magnetometer network stations
(Viljanen and Häkkinen, 1997) are also indicated in Fig. 1 as small black crosses. The fields of view of two of the SuperDARN radars, located at Hankasalmi in Finland and Pykkvibær in Iceland, partly overlap the IMAGE magnetometer network. The location of the Tixie station of the $210 \mathrm{MM}$ (210 deg magnetic meridian) magnetometer network, whose data is also employed, is out of the view of the plot, at 65.67 deg geomagnetic latitude and 196.88 deg geomagnetic longitude. The times labelled with orange crosses on the Cluster footprint and green crosses on the Polar footprint correspond to events discussed in this paper. The Cluster footprint comes into conjunction with the fields of view of the radars from around 19:00 UT onwards, starting with the Pykkvibær (Iceland East) radar, while the Polar footprint comes into conjunction from 20:00 UT. Figure 2 shows the position of the four Cluster spacecraft (true separations) and the Polar spacecraft during this interval in the GSM $x z, x y$ and $y z$ planes. The dotted lines show the model magnetic field lines using the Tsyganenko 1996 model (Tsyganenko and Stern, 1996) while the solid lines show the Cluster spacecraft paths, and the dashed lines show the Polar spacecraft's path. The Cluster spacecraft are all above the centre of the plasma sheet and in the post-midnight sector, and at -16 $\mathrm{R}_{E}$ downtail at 18:00 UT (having later moved to $-18 \mathrm{R}_{E}$ at 24:00 UT). Cluster 3 (Samba, shown in yellow) is closest to the current sheet, Cluster 4 (Tango, red) is furthest down the magnetotail, and Cluster 2 (Salsa, green) is closest to midnight (the $y=0$ axis). The instruments used from the Cluster spacecraft in this study include the Fluxgate Magnetometer (FGM; Balogh et al., 1997), the Plasma Electron and Current Experiment (PEACE; Johnstone et al., 1997), the Cluster Ion Experiment (CIS; Rème et al., 1997), and the Research with Adaptive Particle Imaging Detectors instrument (RAPID; Wilken et al., 1997). The Polar spacecraft (denoted by a black cross) was in the magnetotail close to the equatorial plane, in the post-midnight sector at a distance of $-8 R_{E}$ downtail at 18:00 UT (and later $-9 \mathrm{R}_{E}$ at 24:00 UT). Particle data from the Comprehensive Energetic Particle and Pitch Angle Distribution (CEPPAD; Blake et al., 1995) instrument on Polar are used here.

\section{Data description}

\subsection{IMAGE and $210 \mathrm{MM}$ magnetometer arrays}

In order to provide a context for the Cluster observations and determine timings for the relevant events occurring during the interval, IMAGE ground magnetometer data are shown in Fig. 3. Plots of the $x$ (north-south) component of the magnetic field at selected IMAGE stations and the corresponding filtered data at one station, Tartu (tar), are shown for the 18:00 to 24:00 UT interval. The latter provides information on the presence of Pi2 wave activity. Substorm expansion phase onset is accompanied by $\mathrm{Pi} 2$ pulsations in the ground magnetometer data, which are irregular, damped ULF waves with a period of approximately 20 to $200 \mathrm{~s}$. 

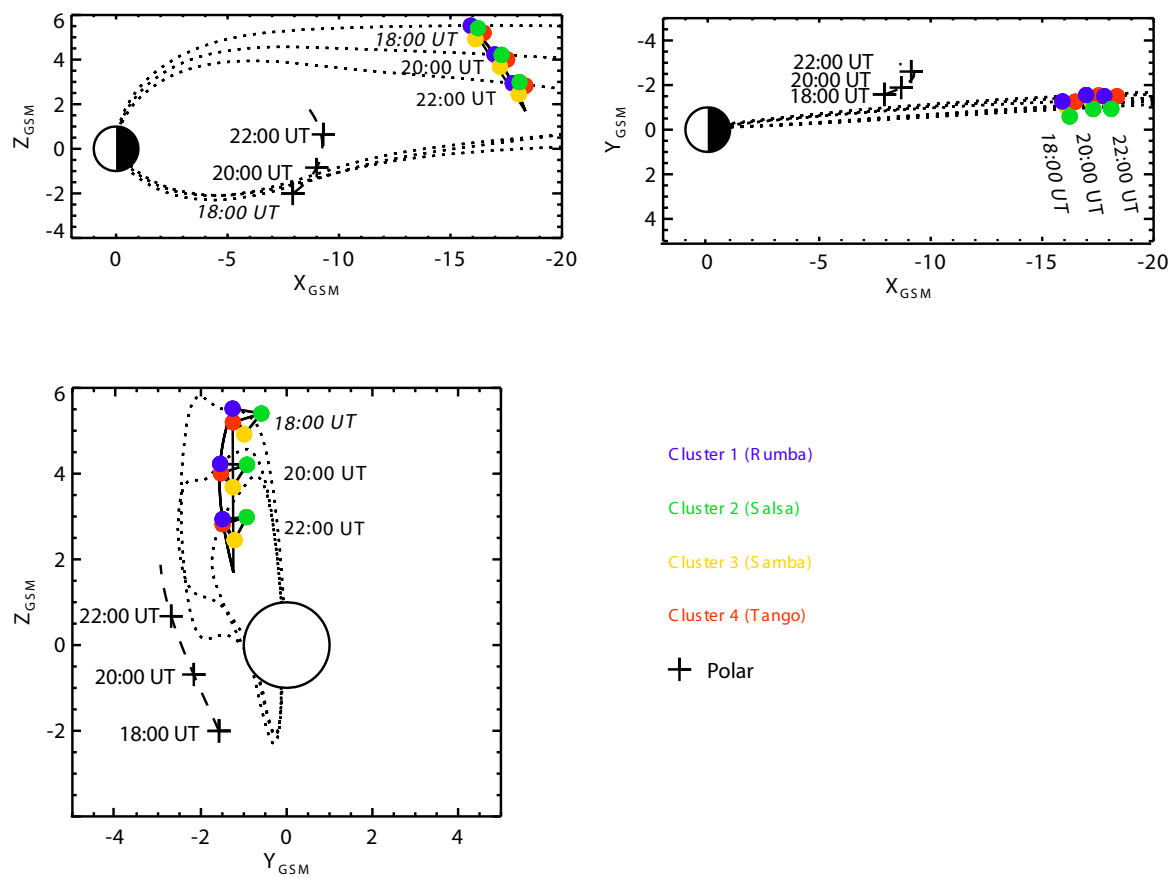

Fig. 2. Orientation of the four Cluster spacecraft and the Polar spacecraft during the 1 September 2002 interval (18:00 to 24:00 UT) in geocentric solar magnetospheric (GSM) coordinates in the $x z, x y$ and $y z$ planes. Blue represents Cluster 1 (Rumba), green Cluster 2 (Salsa), yellow Cluster 3 (Samba) red Cluster 4 (Tango) and a black cross represents the Polar spacecraft. Solid lines show the Cluster spacecraft paths and dashed lines show the Polar spacecraft's path. Dotted lines depict the model magnetic field.

The Pi2 pulsations are related to the SCW that forms during a magnetospheric substorm (e.g. Lester et al., 1983), and thus the onset of Pi2 pulsations may be taken as a proxy for substorm onset (e.g. Rostoker at al., 1980).

The first time of note is 18:23 UT, when Pi2 pulsation onset occurs at all stations, although only one station, tar, is shown. This is accompanied by a slight increase in the $x$ component of up to a few tens of nanotesla (nT) at higher latitudes. This indicates either a pseudobreakup or a full substorm occurring to the east of the stations. Magnetometer data from the Tixie station of the $210 \mathrm{MM}$ magnetometer network are shown in Fig. 4. At 18:23 UT the Tixie station detects a decrease in the $H$ (north-south) component of the magnetic field from $\sim-150 \mathrm{nT}$ to $\sim-250 \mathrm{nT}$. There is also a decrease in the $D$ (east-west) component from $\sim 510 \mathrm{nT}$ to $\sim 460 \mathrm{nT}$. This indicates that a substorm expansion phase onset occurred at 18:23 UT located in this region, rather than a pseudobreakup.

At 22:40 UT and 22:56 UT the IMAGE data (Fig. 3) indicate pseudobreakups at the lower latitude stations, as evidenced by Pi2 pulsations in all components but no major electrojet signature at the higher latitudes. At 23:05 UT the full substorm expansion phase onset occurs at the Sodankylä (sod) and Pello (pel) stations, shortly followed by the Kilpisjärvi (kil) and Ivalo (iva) stations which are at a slightly higher latitude (and close to the Polar spacecraft's orbit footprint). $\mathrm{Pi} 2$ pulsations are detected at all latitudes in all components.

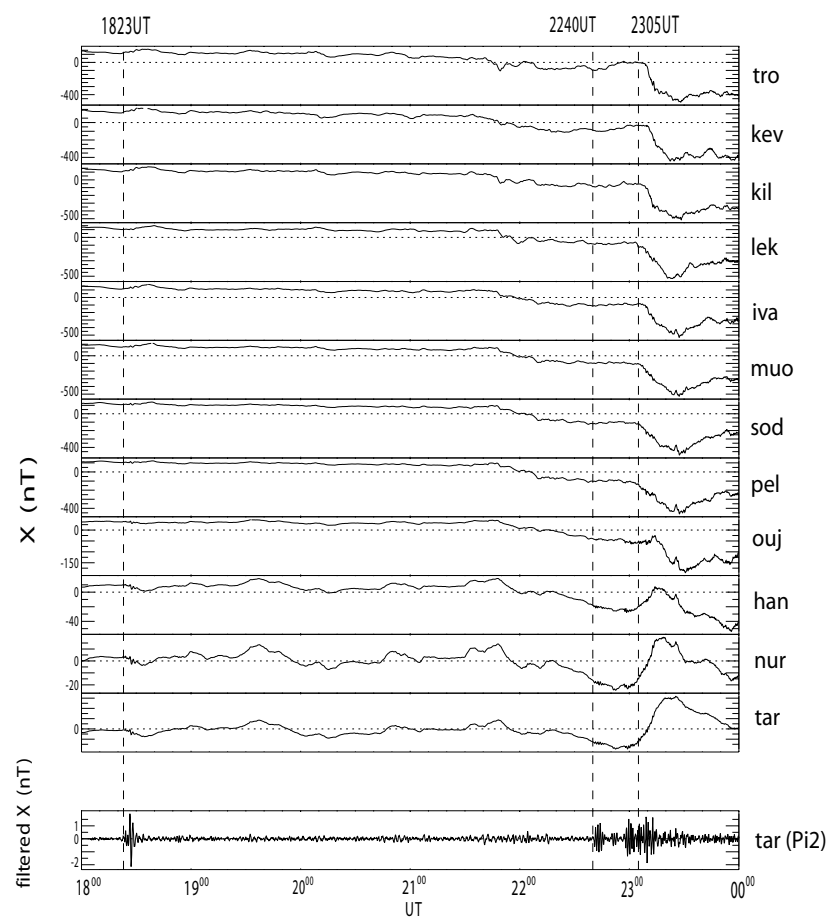

Fig. 3. Top panels: $x$-component of magnetic fields at selected IMAGE magnetometer stations; bottom panel: $x$-component filtered magnetometer data from one example station in the period band 20-200s. 

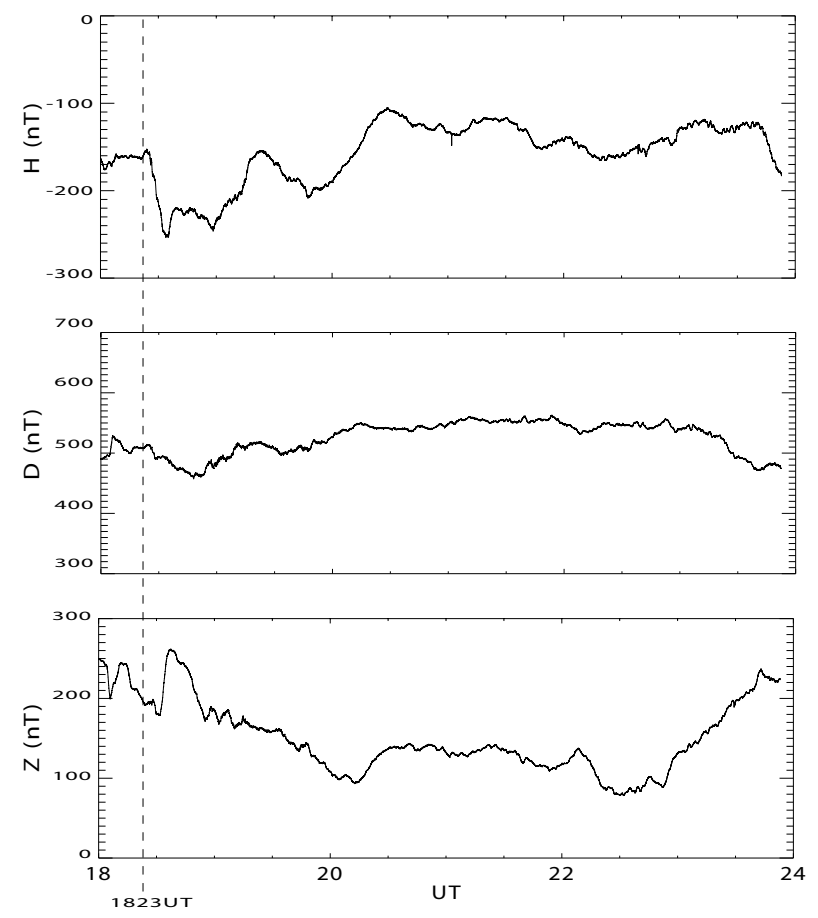

Fig. 4. $210 \mathrm{MM}$ magnetometer data from the Tixie station in $H$, $D$ and $Z$-components, from 18:00 to 24:00 UT. Substorm onset at 18:23 UT indicated by a vertical dashed line.

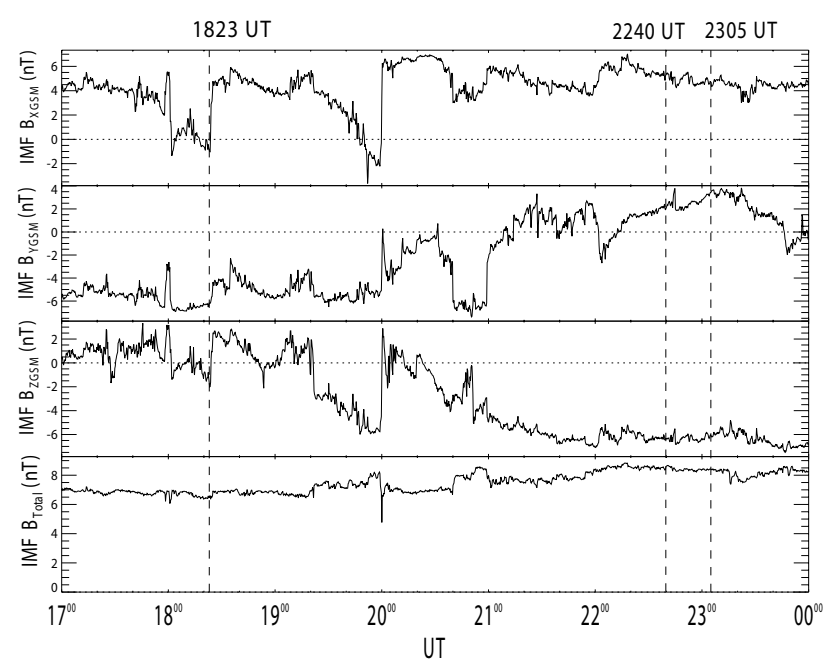

Fig. 5. ACE MAG data lagged by $75 \mathrm{~min}$ (in GSM coordinates). Expansion phase onsets at 18:23 UT and 23:05 UT and a pseudobreakup at 22:40 UT are indicated by vertical dashed lines.

The magnetograms at higher latitudes show a decrease in the $x$-component while the lower latitude stations show an increase at substorm onset, which are signatures of the substorm onset westward electrojet and the SCW, respectively.

\subsection{ACE}

The interplanetary magnetic field (IMF) data during this interval, measured by the magnetometer (MAG) instrument

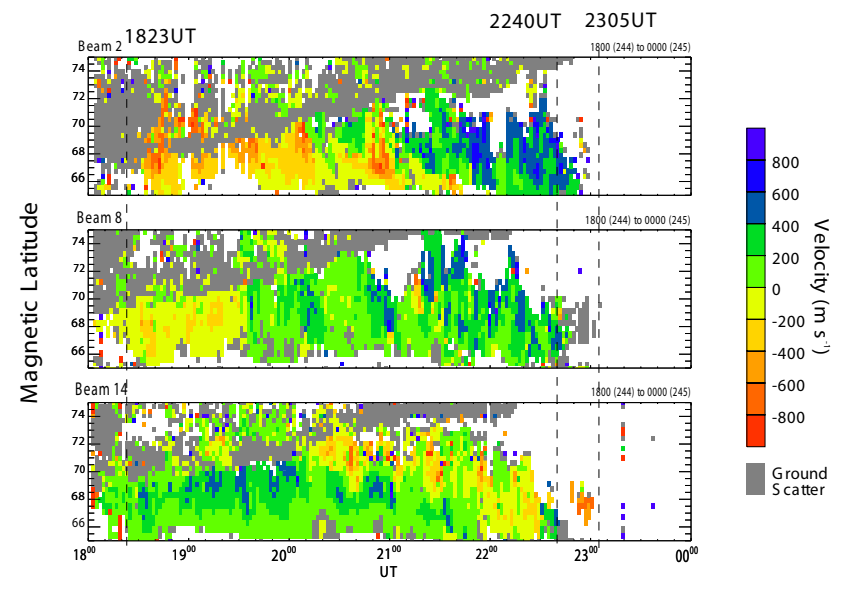

Fig. 6. Range, time and intensity plots for the velocity at three different beams (2, 8 and 14) of the Hankasalmi (Finland) radar during the 18:00 to 24:00 UT interval. Vertical dashed lines represent times of pseudobreakup at 22:40 UT and expansion phase onsets at 18:23 UT and 23:05 UT.

(Smith et al., 1998) on the Advanced Composition Explorer (ACE) spacecraft (Stone et al., 1998), are presented in Fig. 5 (GSM coordinates). These data have been lagged in order to take into account the time taken by the solar wind to reach the Earth's magnetopause from where it is measured at the ACE spacecraft. The lag time for this interval was calculated as $75 \mathrm{~min}$, using both magnetic field data from the Magnetic Fields Measurement (MGF) instrument on the Geotail spacecraft (data not shown) and the technique of Khan and Cowley (1999), from solar wind velocity and density data from the Solar Wind Electron, Proton and Alpha Monitor (SWEPAM) instrument (McComas et al., 1998) on ACE.

In the discussions of the ACE data we quote all times in terms of the lagged time.

Around the first interval at 18:23 UT the (lagged) $\mathrm{B}_{x}$ component of the IMF turns positive. $\mathrm{B}_{y}$ is negative and approximately constant at $-6 \mathrm{nT}$, and $\mathrm{B}_{z}$ turns northwards. $\mathrm{B}_{\text {total }}$ remained steady near $7 \mathrm{nT}$ during this interval. The $\mathrm{B}_{z}$ component of the IMF is southward at around $-6 \mathrm{nT}$ for at least two hours prior to substorm onset at 23:05 UT and remains southward until after 24:00 UT. From 22:15 UT until 23:45 UT the $\mathrm{B}_{x}$ and $\mathrm{B}_{y}$ components of the magnetic field remain approximately constant and do not change sign, with $\mathrm{B}_{x}$ around $5 \mathrm{nT}$ and $\mathrm{B}_{y}$ around $4 \mathrm{nT}$. $\mathrm{B}_{\text {total }}$ remains steady near $8 \mathrm{nT}$ during this interval.

\subsection{Hankasalmi and Pykkvibær radars}

Range-time-velocity plots for three beams $(2,8,14)$ of the Hankasalmi radar (Finland) are shown in Fig. 6 for the 18:00 to 24:00 UT interval. The colour scale is such that reds and yellows denote flow away from the radar, and blues and greens flow towards the radar; grey is ground scatter. 


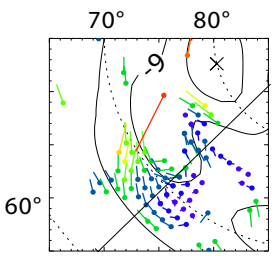

$21 \mathrm{MLT}$

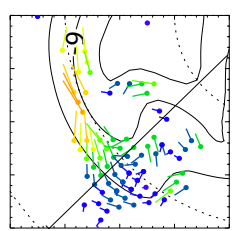

1824UT

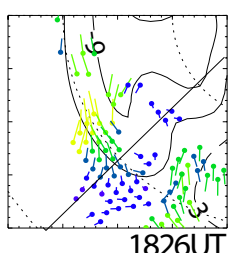

1826UT
Fig. 7. SuperDARN map potential plots at two-minute intervals with the true vectors superposed at 18:22, 18:24 and 18:26 UT on 1 September 2002.

In the Hankasalmi data, the western beams (e.g. beam 2) show a series of intensifications of Doppler line-of-sight velocity $\left(-400 \mathrm{~m} / \mathrm{s}^{-1}\right.$ to $\left.-800 \mathrm{~m} / \mathrm{s}^{-1}\right)$ away from the radar soon after 18:23 UT, beginning at 18:33 UT, while eastern beams (e.g. beam 14) show intensification of velocity towards the radar from 18:30 UT (velocities $400 \mathrm{~m} / \mathrm{s}^{-1}$ to $600 \mathrm{~m} / \mathrm{s}^{-1}$ ). These are seen in all beams and are similar to the signatures seen by Sandholt et al. (2002), who related them to poleward boundary intensifications (Lyons et al., 1999). The directions of these line-of-sight velocities are consistent with westward ion flow. The direction of flow observed by the radar is subsequently reversed at later times; the change in direction occurs at 19:30 UT in the central beams and from 20:10 UT in the western and eastern beams, indicating that the flows here now become eastward. This is due to the rotation of the Earth, and hence the radars are under the flows rather than an actual change in the flow pattern. The outer beams also show velocity intensifications after 20:10 UT that move equatorward over time; they are highly variable and maintained until 22:40 UT. These are signatures of bursty bulk flows (BBFs) in the ionosphere (see Nakamura et al., 2004). After 22:40 UT there is a significant reduction in scatter, and from 22:50 UT scatter is lost completely, first from the eastern beams from 22:40 UT and then from the western beams.

The Pykkvibær radar (Iceland east) data (not shown) have intensifications towards the central beams of the radar from 18:45 UT onwards. Exceptionally strong flows toward the radar $\left(600 \mathrm{~m} / \mathrm{s}^{-1}\right.$ to $\left.800 \mathrm{~m} / \mathrm{s}^{-1}\right)$ are seen in beams 6 to 12 from 19:30 UT onwards. At 22:40 UT there is some intensification of flow toward the radar on the northern beams 0 to 7 (velocities $400 \mathrm{~m} / \mathrm{s}^{-1}$ to $600 \mathrm{~m} / \mathrm{s}^{-1}$ ). This intensification persists until 23:14 UT when it is abruptly lost. After this time much of the scatter is lost such that only ground scatter and some low-velocity scatter remains.

\subsection{SuperDARN}

The map potential analysis technique (Ruohoniemi and Baker, 1998) for the SuperDARN data was used to map line-of-sight velocity measurements from the Northern Hemisphere radars (Kodiak, Prince George, King Salmon, Pykkvibær, Hankasalmi, Goose Bay, Saskatoon, Kapuskasing and Stokkseyri) onto a global grid to provide large-scale

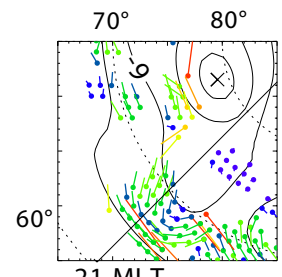

21 MLT

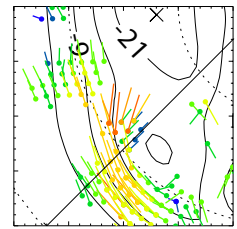

1844UT
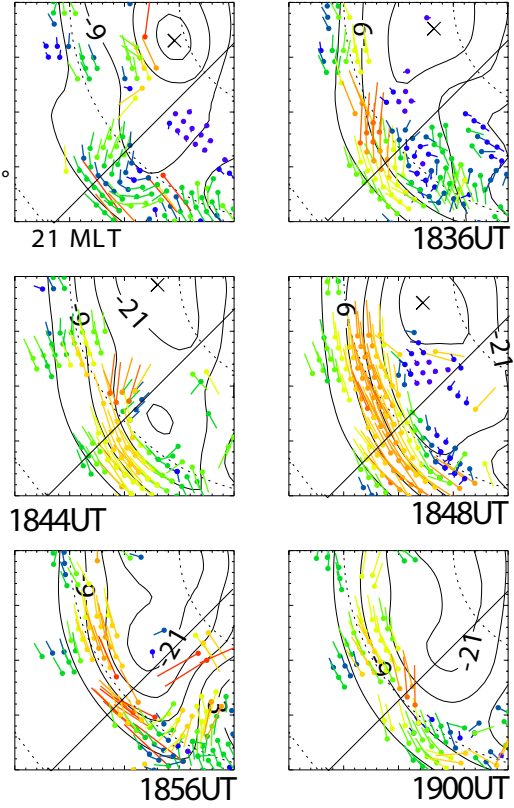

1836UT

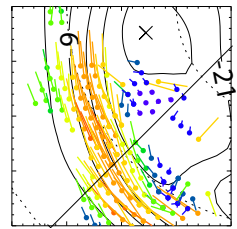

1848UT

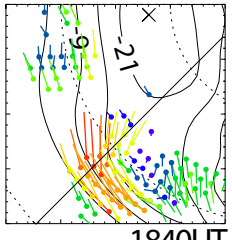

1840UT
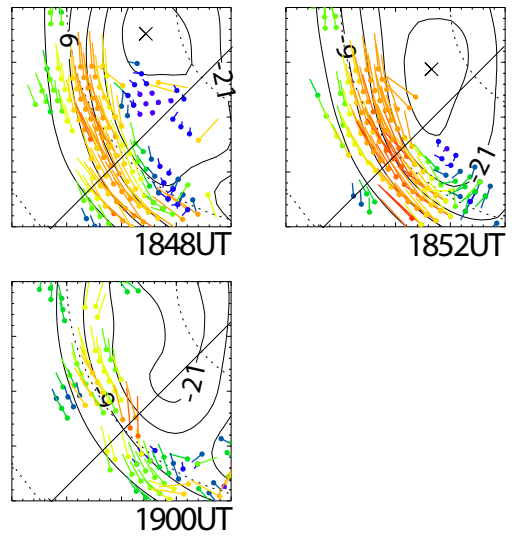

Fig. 8. SuperDARN map potential plots at four-minute intervals with the true vectors superposed from 18:32 until 19:00 UT on 1 September 2002.

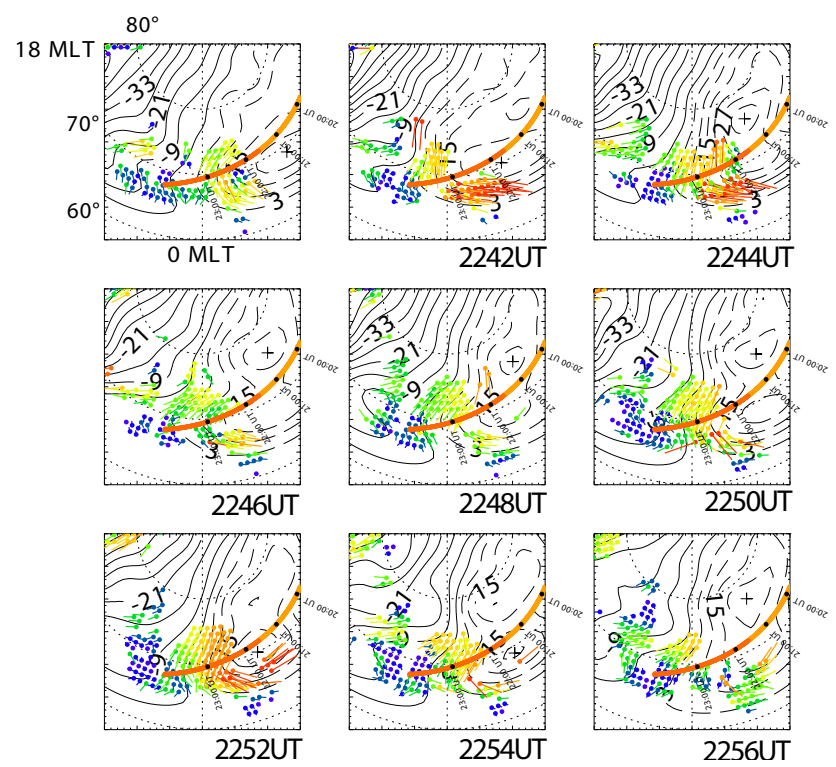

Fig. 9. SuperDARN map potential plots at two-minute intervals with the true vectors superposed from 22:40 until 22:56 UT on 1 September 2002 and with Cluster 1 footprint also superposed.

global convection maps for the interval of interest. SuperDARN map potential plots presented here show pre-midnight (Figs. 7 and 8) and post-midnight (Figs. 9 and 10) sector sections of large-scale convection maps and so-called true vectors (see Ruohoniemi and Baker, 1998), derived from line-ofsight data from the SuperDARN radars for times of interest near each of the substorm expansion phase onsets. 


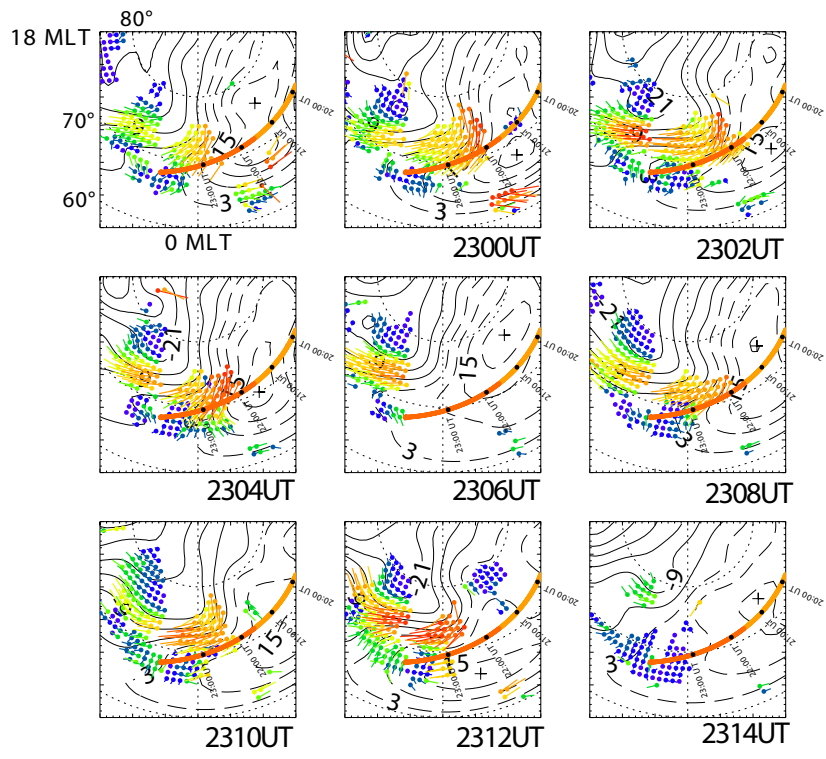

Fig. 10. SuperDARN map potential plots at two-minute intervals with the true vectors superposed from 22:58 until 23:14 UT on 1 September 2002 and with Cluster 1 footprint also superposed.

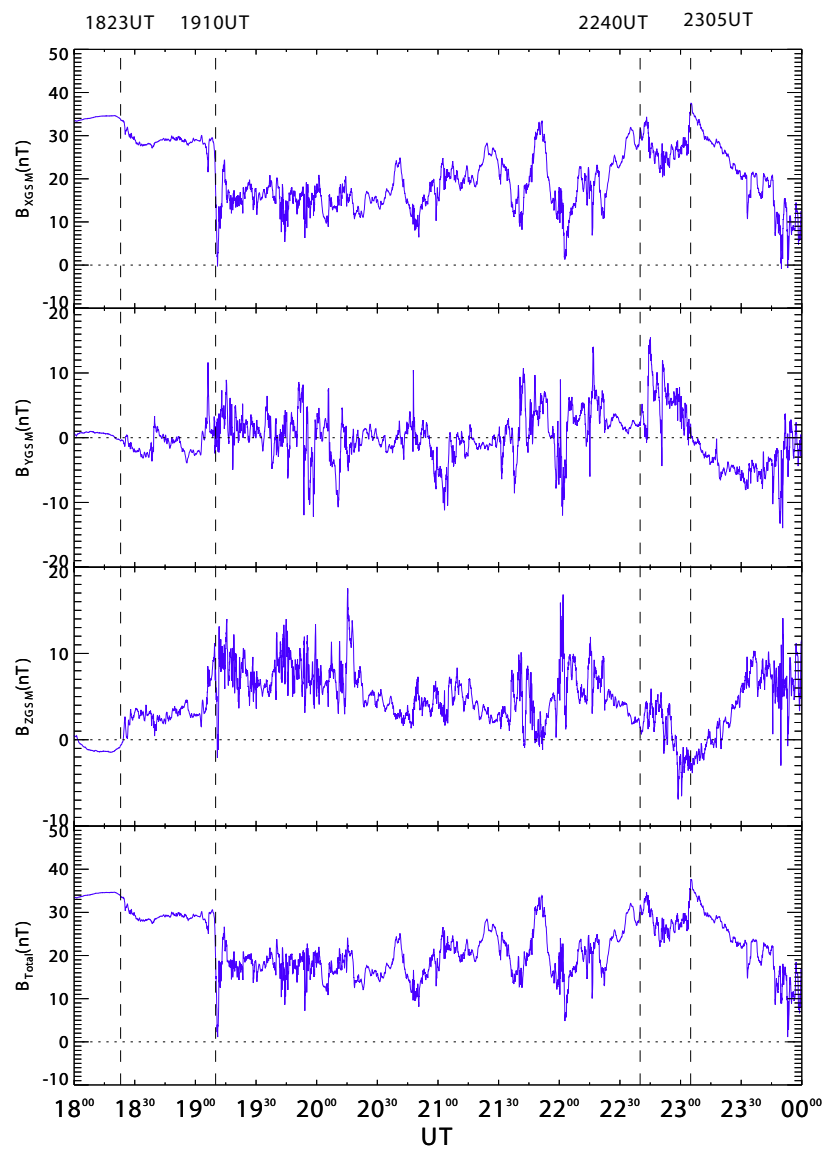

Fig. 11. Cluster FGM data for 1 September 2002 (18:00 to 24:00 UT interval). The $\mathrm{B}_{x}, \mathrm{~B}_{y}, \mathrm{~B}_{z}$-components and $\mathrm{B}_{\text {total }}$ in GSM coordinates are shown for the Cluster 1 spacecraft (Rumba).
The Cluster footprint is shown where it is within the map limits (Figs. 9 and 10 only).

Dotted black lines depict constant latitude and MLT, while dashed and solid black lines depict contours of potential. The true vectors shown are colour-coded by magnitude such that slower velocities are blue and faster velocities are red.

The map potential plots in Fig. 7 show that at 18:24 UT (21 MLT, $60^{\circ}$ to $80^{\circ}$ section of plot shown) there is an intensification of the velocity in the $20 \mathrm{MLT}, 65^{\circ}$ to $70^{\circ}$ latitude region, to a velocity of $800 \mathrm{~m} / \mathrm{s}^{-1}$. From 18:32 UT until 19:00 UT (Fig. 8) there are strong westward flows in the premidnight sector ( $21 \mathrm{MLT}, 60^{\circ}$ to $80^{\circ}$ section of plot shown). Figure 9 (00 MLT, $60^{\circ}$ to $80^{\circ}$ section of plot shown) shows enhancements in flows from 22:40 UT until 22:56 UT in the midnight sector (00 MLT), just equatorward of the estimated footprint of the Cluster spacecraft at that same time. In particular there are intensifications of the velocity at 22:42 and 22:52 UT. These intensifications occur at $65^{\circ}$ to $75^{\circ}$ latitude, and reach values of $1000 \mathrm{~m} / \mathrm{s}^{-1}$. From 22:58 UT strong, antisunward flows continue in the 00 MLT region, as can be seen in Fig. 10 , centred around $65^{\circ}$ to $75^{\circ}$ latitude, to a velocity of around $1000 \mathrm{~m} / \mathrm{s}^{-1}$ (00 MLT, $60^{\circ}$ to $80^{\circ}$ section of plot shown). This is maintained until 23:12 UT to a velocity of $800 \mathrm{~m} / \mathrm{s}^{-1}$, after which the scatter is lost. Particularly strong flows occur at 23:04 UT.

\subsection{Cluster FGM}

Figure 11 presents the Cluster FGM data for the 18:00 to 24:00 UT interval for the GSM $\mathrm{B}_{x}, \mathrm{~B}_{y}, \mathrm{~B}_{z}$ components and $\mathrm{B}_{\text {total }}$ at Cluster 1 (Rumba). In the $\sim 20$ min prior to the first substorm expansion phase at 18:23 UT, the field is dominated by the $x$-component, with both $y$ and $z$ components small, with values $\sim 1 \mathrm{nT}$, although we note that the $z$-component is negative. The $x$-component and hence total field both increase up to the time of expansion phase onset. Following the substorm expansion phase onset at 18:23 UT, there is a small reduction in $\mathrm{B}_{x}$ and $\mathrm{B}_{\text {total }}$, and $\mathrm{B}_{z}$ changes sign from negative to positive.

The field magnitude reduces from $\sim 34 \mathrm{nT}$ to $\sim 28 \mathrm{nT}$ over an interval of $\sim 15 \mathrm{~min}$, and is then steady until $\sim 19: 10$ UT. There is then a major reduction in the field, almost to zero magnetic field, which lasts for a few minutes before recovering to a value of $25 \mathrm{nT}$. After this the magnetic field is highly variable, indicative of the spacecraft being in the plasma sheet at this time. From 22:00 UT the magnetic field generally increases mainly due to an increase in $\mathrm{B}_{x}$. At 22:40 UT, the time of the first pseudobreakup in the second growth phase, there is a small increase in $B_{\text {total }}$. At 23:05 UT there begins a reduction in the field magnitude by a factor of two over the next hour. After 23:45 UT, the $\mathrm{B}_{x}$ and $\mathrm{B}_{z}$ components become comparable in magnitude, $\sim 10 \mathrm{nT}$. There is also a second brief interval when total field approaches $0 \mathrm{nT}$, at 23:53 UT. 
Figure 12 shows the Cluster FGM data for four 20-min intervals which encompass the times of interest: the expansion phase onsets at 18:23 and 23:05 UT, the pseudobreakup at 22:40 UT and a new time of interest, 19:10 UT.

Again, data are plotted in GSM for the $\mathrm{B}_{x}, \mathrm{~B}_{y}, \mathrm{~B}_{z}$ components and $\mathrm{B}_{\text {total }}$, and data from the four Cluster spacecraft are colour coded, as indicated on Fig. 12. In the first panel (upper left), the field is approximately constant until 18:21 UT after which it starts to decrease. From 18:25 UT this decrease is quicker and occurs at all spacecraft simultaneously, indicating a temporal, rather than a spatial, change in the magnetic field at the Cluster spacecraft at that time. There is also evidence of wave activity initiated at the onset, as $\mathrm{Pi} 2$ waves are present from this time.

At 19:10 UT (upper right panel) the FGM data show a sudden and brief excursion whereby all components briefly approach $0 \mathrm{nT}$, then return to approximately their previous values. This occurs in the order Cluster 4 , then Cluster 1 and Cluster 2, then finally Cluster 3, and so indicates that the spacecraft are encountering a structure in the magnetic field, rather than there being some temporal change in the magnetic fields at that time. The spacecraft exit the structure in the same order as they enter. This indicates that the structure moves completely over the four spacecraft. As the magnetic field is very close to zero, this would indicate that the spacecraft are in a diamagnetic cavity. The order in which the spacecraft encounter and leave this structure indicates that it is coming in from the tail towards the Earth. It is also moving down on to the spacecraft, in the negative $z$-direction, as the Cluster 3 spacecraft has the smallest GSM $z$-value. This feature is the subject of further work (see Draper et al., 2004) and will not be discussed in detail in this paper.

At 22:40 UT (lower left panel) the FGM data show a peak in $\mathrm{B}_{x}$ which decreases from $\sim 34 \mathrm{nT}$ at $22: 44 \mathrm{UT}$ to $\sim 24 \mathrm{nT}$ at 22:50 UT, simultaneously at Cluster 1, Cluster 2 and Cluster 4, with Cluster 3 exhibiting broadly similar behaviour during this interval, but not following the other spacecraft as exactly. This is perhaps due to Cluster 3 being closer to the current sheet than the other three spacecraft. The $\mathrm{B}_{y}$ component also decreases from $\sim 15 \mathrm{nT}$ at $22: 44 \mathrm{UT}$ to $\sim 0 \mathrm{nT}$ at 22:50 UT.

However, at Cluster 3 the decrease in the $\mathrm{B}_{y}$ component lags that at the other spacecraft by a few minutes.

At 23:05 UT (lower right panel) the $\mathrm{B}_{x}$ component of the magnetic field reaches a peak at around $38 \mathrm{nT}$ then decreases at all spacecraft simultaneously. Again, Cluster 3 shows slightly different variations but in general the agreement between the other spacecraft is very close. The $\mathrm{B}_{y}$ component begins a gradual decrease from $\sim 0 \mathrm{nT}$ at this time, while the $\mathrm{B}_{z}$ component begins a gradual increase in $\sim-4 \mathrm{nT}$. $\mathrm{B}_{\text {total }}$ begins to decrease from $\sim 38 \mathrm{nT}$, following the dominant $\mathrm{B}_{x}$ component, and decreases by a factor of two over the next hour. This reduction is seen at all spacecraft and so is a feature that occurs over the scale size of the spacecraft separation. In all components there are fewer high-frequency oscillations during this time, indicating that the spacecraft may have exited the plasma sheet and re-entered the lobe. This

\section{CLUSTER}

Fluxgate Magnetometer (FGM)
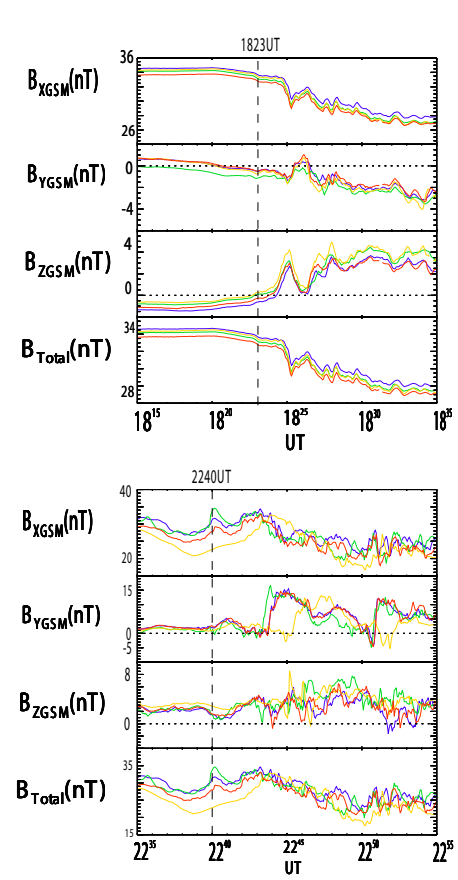

$1^{\text {st }}$ September 2002

$$
\text { custer: |partal }
$$
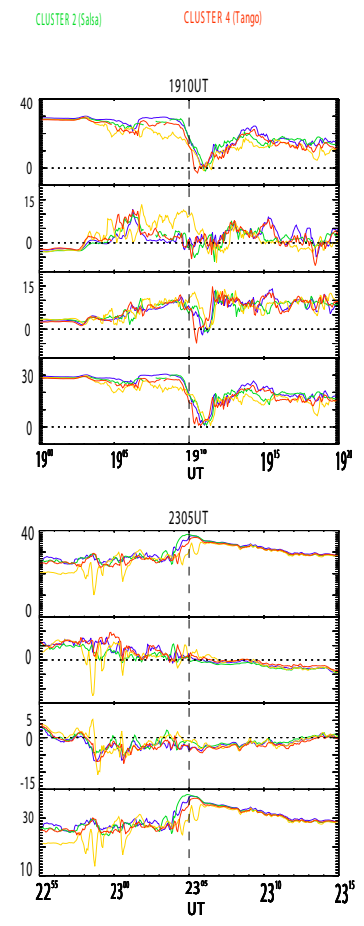

Fig. 12. Cluster FGM data for 1 September 2002 in the $\mathrm{B}_{x}, \mathrm{~B}_{y}, \mathrm{~B}_{z}$ and $B_{\text {total }}$ GSM coordinates for intervals centred on 18:23, 19:10, 22:40 and 23:05 UT. Cluster 1 (Rumba) is shown in blue, Cluster 2 (Salsa) in green, Cluster 3 (Samba) in yellow and Cluster 4 (Tango) in red.

is now corroborated in the Cluster plasma data from CIS, PEACE and RAPID.

\subsection{Cluster plasma data}

The top six panels of Fig. 13 show the CIS ion density and velocity data from three spacecraft, Cluster 1 , Cluster 3 and Cluster 4 for this interval. Note that the CIS instrument on Cluster 2 was not operational at the time. Prior to 19:03 UT (indicated by the second vertical dashed black line on plot) all three spacecraft measure low ion densities of $\sim 0.01 \mathrm{~cm}^{-3}$. At 19:03 UT there is an increase in the low-energy ion densities at all spacecraft to $\sim 0.1 \mathrm{~cm}^{-3}$ at Cluster 1 and Cluster 3 , and to $\sim 1.0 \mathrm{~cm}^{-3}$ at Cluster 4 . This is accompanied by a sharp increase in the $\mathrm{v}_{x}$ component of the velocity from $\sim 0 \mathrm{~km} / \mathrm{s}^{-1}$ to $\sim 1000 \mathrm{~km} / \mathrm{s}^{-1}$, with some fluctuations. This indicates bursty flow towards Earth which continues until 19:15 UT. At 23:05 UT there is a sharp decrease in the density at all spacecraft, returning to $\sim 0.01 \mathrm{~cm}^{-3}$. These data indicate that the spacecraft are in the plasma sheet from 19:03 UT until the second substorm onset at 23:05 UT, consistent with the FGM data, and in the lobe before 19:03 UT and after 23:05 UT. 

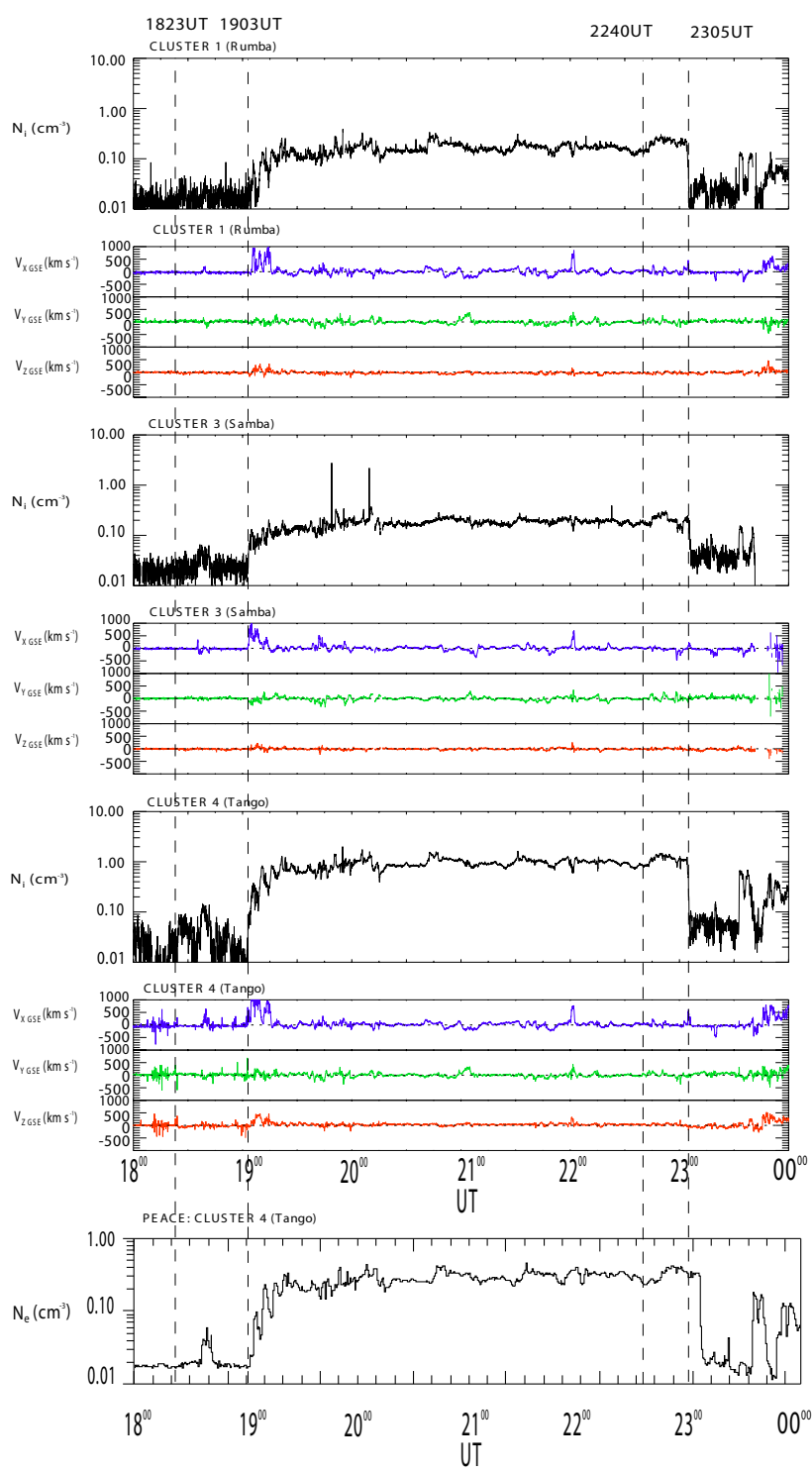

Fig. 13. Top six panels: Cluster CIS density and velocity data from the three spacecraft for 1 September 2002 (18:00 to 24:00 UT interval). Bottom panel: Cluster PEACE density data from Cluster 4 for the same interval.

The bottom panel of Fig. 13 shows the PEACE electron density data from Cluster 4 for this interval. Data from this spacecraft are shown as the ASPOC (Riedler et al., 1997) spacecraft potential control device is switched on in order to avoid interference by photoelectrons, thereby making the density data more reliable. At around 19:03 UT the lowenergy electron density at Cluster 4 begins to increase from $\sim 0.01 \mathrm{~cm}^{-3}$ to $\sim 0.1 \mathrm{~cm}^{-3}$ at $19: 10$ UT. This higher density is maintained until 23:05 UT when there is a sudden decrease back to $\sim 0.01 \mathrm{~cm}^{-3}$. This is also consistent with Cluster being located in the plasma sheet during this interval. Analysis of the plasma sheet boundary layer (PSBL) crossings using PEACE data indicates that at 19:03 UT the unit normal of the boundary was $(0.01,-0.56,0.83)$ in GSE coordinates, with

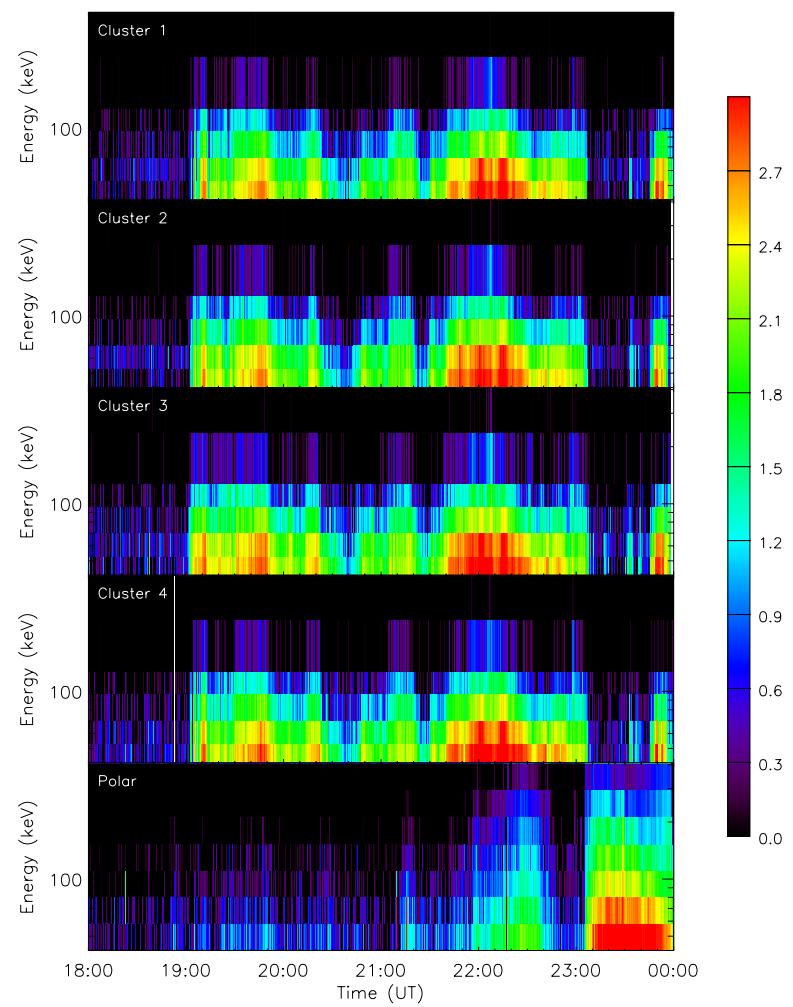

Fig. 14. First four panels: Cluster RAPID IES data for 1 September 2002 (18:00 to 24:00 UT interval). Bottom panel: Polar CEPPAD IES data for the same interval.

a velocity along the normal of $30 \mathrm{~km} / \mathrm{s}^{-1}$. This was for a crossing from the lobe into the plasma sheet which occurred in the direction expected given the orientation of the spacecraft. At 23:05 UT the spacecraft re-entered the lobe from the plasma sheet, with a corresponding unit normal of $(0.02$, $-0.34,-0.94)$ and normal velocity component $38 \mathrm{~km} / \mathrm{s}^{-1}$.

The RAPID-IES omni-directional electron flux data are shown in Fig. 14 (first four panels). The IES shows that the flux of electrons in the $40-400 \mathrm{keV}$ range increases by several orders of magnitude in the interval 19:03 UT to 23:05 UT (with fluctuations). The IIMS data (not shown) indicate that the flux of protons in the $30-100 \mathrm{keV}$ range increases during the same interval. This is also consistent with Cluster being in the plasma sheet from 19:03 UT until 23:05 UT.

From 22:40 UT there is a reduced electron flux, suggesting growth phase effects are now present at the Cluster spacecraft. At 23:05 UT there is a sharp decrease at all energy levels at all four spacecraft as they exit the plasma sheet into the lobe.

\subsection{Polar CEPPAD}

To have an idea of the particle populations closer to Earth for this interval, data from the Polar CEPPAD-IES, which is virtually identical to the RAPID-IES on Cluster, were used. The data are shown in the bottom panel of Fig. 14. 
Polar at this time is located at $9 \mathrm{R}_{E}$ downtail, in the postmidnight sector. The CEPPAD-IES data show a decrease in the electron count rate in the same energy range as the RAPID data from 22:40 UT. This drop-out is indicative of the plasma sheet thinning and growth phase. This is followed by a sudden plasma injection at 23:05 UT, indicating expansion phase onset.

\subsection{LANL geosynchronous energetic particle data}

The low energy electron data from the LANL geosynchronous spacecraft (Fig. 15) indicate that a dispersionless injection of plasma occurs at geosynchronous orbit $\left(\sim 6.6 \mathrm{R}_{E}\right)$ at $\sim 18: 27$ UT. This is detected by two of the LANL spacecraft, which at this time are located in the postmidnight sector, close to the geographic equator.

This plasma injection into the magnetotail is consistent with a substorm expansion phase onset occurring at 18:23 UT. There is also a plasma injection in the midnight sector at geosynchronous orbit around the time of the second substorm at 23:05 UT, also detected by the LANL spacecraft.

\section{Discussion}

A number of events were observed during this interval which are seen by many different instruments, both ground-based and space-based, which helps to build an accurate picture of what is happening in both the magnetosphere and ionosphere simultaneously during the two substorm expansion phases described above.

The first substorm expansion onset occurred at 18:23 UT, at which time the Cluster plasma instruments demonstrate that the spacecraft are in the tail lobe. There is a dispersionless plasma injection at 18:27 UT in the post-midnight sector of the magnetotail at geosynchronous orbit, detected by two of the LANL spacecraft, consistent with substorm onset. The magnitude of the onset signature is weak due to the displacement of the stations from the onset location. This is consistent with the few minutes delay between the ground magnetometer signature and the plasma injection at geosynchronous orbit.

Also, a substorm signature is seen at Cluster in the FGM data at 18:25 UT, with a simultaneous reduction in both the total magnetic field and in $\mathrm{B}_{x}$ at all spacecraft, indicating a temporal change in the magnetic field. The onset region is located to the east of the IMAGE ground magnetometer stations, at the location of the Tixie magnetometer station, where a clear substorm onset signature is detected. We thus define this as a substorm expansion phase rather than pseudobreakup. The Cluster spacecraft at this time are located at $(-16,-1,5) \mathrm{R}_{E}$ in GSM coordinates. FGM $\mathrm{B}_{z}$ also changes sign from negative to positive at expansion phase onset and since no plasma sheet signature is seen in the plasma data, this is interpreted as a major re-orientation of the lobe field. Although the Cluster spacecraft are not in the optimum position for the measurement of a substorm onset, the detection

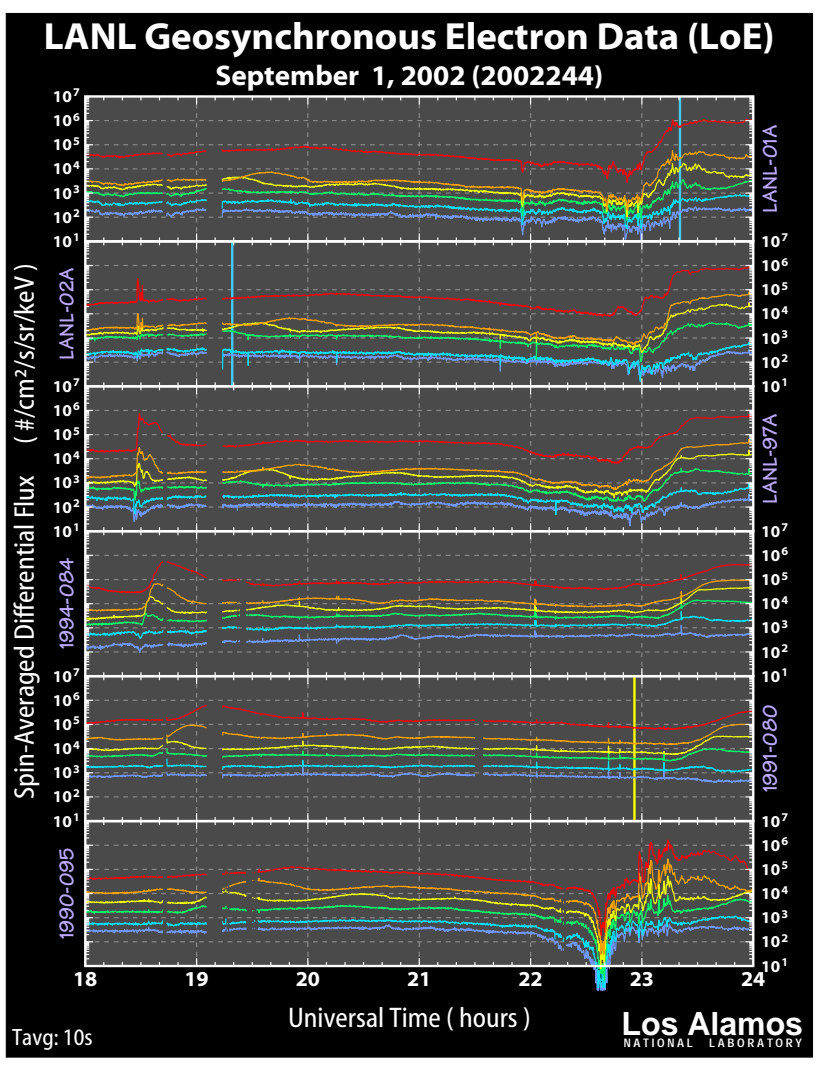

Fig. 15. LANL low energy electron data from the SOPA instrument are shown for 1 September 2002 (18:00 to 24:00 UT interval).

of these signatures at onset indicates that this event is a largescale feature. The IMF $\mathrm{B}_{x}, \mathrm{~B}_{y}$ and $\mathrm{B}_{z}$ components fluctuate during this time; in particular, both $\mathrm{B}_{z}$ and $\mathrm{B}_{x}$ turn positive at 18:23 UT. The northward turning of IMF $\mathrm{B}_{z}$ will decrease the rate of dayside reconnection, but wider implications cannot be drawn from this single data set. Due to the substorm expansion phase onset, the magnetic field in the tail decreases from 18:23 UT. Hence, the reconnection at the dayside is less than in the magnetotail.

A brief enhancement of the ionospheric sunward flow near $70^{\circ}$ magnetic latitude and 20 MLT accompanies expansion phase onset at $\sim 18: 23$ UT but a more significant enhancement of the sunward flow is seen some 5 to 10 min after expansion phase onset. A series of enhancements at the poleward edge of the scatter at the Hankasalmi radar are seen over the next $60 \mathrm{~min}$ or so. Such enhancements have been discussed by Sandholt et al. (2002), who observed 6 discrete poleward boundary intensifications (PBIs) of the auroral oval during a substorm event occurring on the 12 December 1999. These were identified by an equatorward expansion of equatorward flow in the late expansion phase using the Hankasalmi (Finland) SuperDARN radar, as is also seen in the late expansion phase of the first substorm after 18:23 UT. Sandholt and co-workers concluded that bursty bulk flows (BBFs) from the magnetic reconnection site may be a phenomena of late substorm expansion phase, resulting 
in the auroral and convection events seen at that time, and which may perhaps account for the flow enhancements seen in this particular event.

We see no evidence for BBFs in the Cluster data at this time, which is probably due to the Cluster spacecraft being in the northern tail lobe. Therefore we are unable to confirm the interpretation by Sandholt et al. the radar signatures from this event. We note, however, that the flow enhancements observed by the radars do not have coincident magnetic signatures which are characteristic of poleward boundary intensifications (Lyons et al., 1999). This suggests that either these flow enhancements are not related to PBIs or the magnetic signature is too weak and/or too localized to be detected by the IMAGE magnetometers in this case. We also note the lack of lobe signatures associated with the radar flow enhancements, unlike the signature in the lobe at expansion phase onset.

At 19:03 UT the CIS data show that the low-energy ions increase their $x$-component of velocity (flow towards Earth), which is maintained until 19:15 UT. This is a signature of ion beams in the PSBL (Eastman et al., 1984), indicating that the Cluster spacecraft cross the PSBL. The low-energy ion density also increases at 19:03 UT, and is maintained until 23:05 UT. The PEACE data similarly show an increase in the density of low-energy electrons from 19:03 UT. The density reaches its maximum value at 19:10 UT, and remains there until 23:05 UT when there is a sudden decrease in density. Moreover, the RAPID data show an increase in the number of high-energy electrons and ions from 19:03 UT, until a sudden decrease at 23:05 UT. RAPID and PEACE data are both consistent with the Cluster spacecraft entering the plasma sheet after crossing the PSBL and remaining there until 23:05 UT when they suddenly re-enter the lobe. The unit normal at which the spacecraft cross the PSBL into the plasma sheet at 19:03 UT indicates that it is inclined mainly in the $y-z$ plane, with a negative $y$-component. The boundary is travelling at $30 \mathrm{~km} / \mathrm{s}^{-1}$ which is slower than typical values (Dewhurst et al., 2004).

Pseudobreakups are seen by the IMAGE ground magnetometers at 22:40 and 22:56 UT prior to the second expansion phase onset. The IMF as seen at ACE (lagged by $75 \mathrm{~min}$ ) has been southward from around 20:55 UT (and remains southwards until after 24:00 UT), and all components have been approximately constant from 22:15 UT (and remain so until around 23:45 UT). Scatter from the Hankasalmi radar begins to be lost following the first pseudobreakup, first from the eastern beams and finally from the western beams by 23:00 UT, after which no further scatter is seen in the Hankasalmi radar data. The Pykkvibær radar shows an intensification of westward flow (toward the radar) at 22:40 UT, maintained until 23:14 UT after which scatter is also lost. At 22:42 UT and 22:52 UT the SuperDARN data show intensifications in the flow in the midnight sector at $65^{\circ}$ to $75^{\circ}$ latitude and these enhanced flows are associated with the pseudobreakups. The Cluster FGM data show a peak in the $\mathrm{B}_{x}$ component of the magnetic field at Cluster 1,2 and 4 at 22:40 UT, which decreases simultaneously at all spacecraft from 22:44 UT until 22:50 UT. The $\mathrm{B}_{y}$ component also decreases from 22:44 UT, until 22:50 UT. This feature shows some variability in its velocity as it moves towards the 01 MLT region. Furthermore, Polar CEPPAD data shows a dropout in the near-Earth particle populations at $\sim 22: 40 \mathrm{UT}$, the time of the first pseudobreakup.

A full substorm onset occurs at 23:05 UT, as seen at the IMAGE magnetometer stations. At this time, $\mathrm{Pi} 2$ pulsations commence at all latitudes, in all components of the magnetic field. The higher latitude stations show a decrease in the $\mathrm{B}_{x}$ component as expected at substorm onset, while the lower latitude stations show an increase in the $\mathrm{B}_{x}$ component, indicative of the SCW. Onset is detected at stations equatorward of the ionospheric projection of the Polar spacecraft's path first, followed by stations in its path. This implies that the onset location in the tail was earthward of the Polar spacecraft. The Hankasalmi radar has lost much of the ionospheric scatter at this time, but the SuperDARN map potential data indicate that there are intensified flows from 22:58 UT in the $00 \mathrm{MLT}, 65^{\circ}$ to $75^{\circ}$ latitude region. This is maintained, with some further intensification, until 23:12 UT after which the ionospheric scatter is completely lost in the midnight sector. The strongest flows during this time are now poleward of the location of the flows during pseudobreakups. The $\mathrm{x}$-component of the magnetic field at all Cluster spacecraft reaches a peak at 23:05 UT, then decreases at all spacecraft simultaneously such that over the next hour it decreases by a factor of two. The $\mathrm{B}_{y}$ component also begins to decrease at this time, while the $\mathrm{B}_{z}$ component increases. Also, there are fewer fluctuations in the magnetic field from 23:05 UT. This is indicative of the dipolarization of the magnetotail and reduction in field magnitude at the expansion phase onset, consistent with the indication from the Cluster particle data that the spacecraft re-enter the lobe at 23:05 UT. However, the plasma data show no signature for the PSBL at 23:05 UT, indicating that either the exit to the lobe occurred more rapidly than the entry or there were no flows in the PSBL at this time. The near-Earth Polar CEPPAD data also show a plasma injection at 23:05 UT, consistent with substorm onset. The LANL geosynchronous spacecraft also show a plasma injection at this time. The unit normal at which the Cluster spacecraft cross the PSBL to return to the lobe indicates that it is inclined mainly in the $y-z$ plane, with both $y$ and $z$-components negative. The boundary is travelling at $38 \mathrm{~km} / \mathrm{s}^{-1}$ which is faster than the previous entry but again slower than typical values previously found (Dewhurst et al., 2004).

It is interesting to note that the magnetic field in the magnetotail lobe decreases from 23:05 UT despite that the IMF as seen at ACE remains steady and southward. This implies that magnetic flux is being lost from the magnetotail due to tail reconnection faster than it is being replaced by reconnection at the dayside magnetopause, as in the earlier substorm. 


\section{Summary and conclusions}

The first substorm event at 18:23 UT on the ground indicates that the ground-based magnetometers see the substorm event first, followed by the Cluster spacecraft, two of the geosynchronous LANL spacecraft and ionospheric radars, respectively. The Cluster spacecraft at this time are not ideally placed to observe substorm signatures in the tail, being in the lobe, and well away from the plasma sheet. Nevertheless, the Cluster spacecraft detect a substorm signature in the lobe as demonstrated by the FGM data presented above. The loss of flux in the lobe occurs at the substorm expansion phase onset, indicating that reconnection either began at expansion phase onset or had begun somewhat earlier. Reconnection at the dayside is reduced. Furthermore, we estimate that reconnection lasted only for the first $15 \mathrm{~min}$ or so of the expansion phase, corresponding to the time during which magnetic flux in the magnetotail was decreasing. This indicates that the effects of the substorm at the location of the Cluster spacecraft, in the post-midnight sector of the lobe region of the magnetotail, were of relatively short duration.

The second substorm onset at 23:05 UT is seen simultaneously on the ground, in the magnetotail and at the Polar spacecraft's near-Earth position. The response in the ionosphere takes one minute longer to develop than at the spacecraft. The implication that reconnection takes place within the Polar orbit at $9 \mathrm{R}_{E}$ downtail needs further study, as this value is much closer to Earth than the accepted location of the NENL at 20 to $30 \mathrm{R}_{E}$ downtail. The Cluster spacecraft cross the PSBL very rapidly, such that the signature in the particle data shows only their exit to the lobe. While in the lobe, magnetic flux is again lost, which implies that reconnection is taking place but over a much longer time scale. Dipolarization takes place at 23:05 UT, which indicates that reconnection must be taking place at the NENL at this time. This means that information propagation must be from the NENL towards Earth, as there would not be sufficient time for information to be propagated from the inner current sheet to the NENL and back again, given the timings presented here. Thus, this event would appear to better fit the NENL model for substorm onset than the CCI model.

In both events enhanced ionospheric flows occur following the expansion phase and in the case of the second event in association with the pseudobreakup. There is a major difference between the location of the flows stimulated by the pseudobreakup and expansion phase in terms of their location, the former located equatorward of the latter. This requires further study to see if this is repeatable.

Acknowledgements. The authors would like to thank the PIs of the SuperDARN radars from which data have been presented; the Cluster Principal Investigators for the FGM (A. Balogh), CIS (H. Rème), PEACE (A. Fazakerley) and RAPID (P. Daly) instruments; the institutes who maintain the IMAGE magnetometer array and also the Principal Investigator institute for IMAGE, the Finnish Meteorological Institute; the Solar-Terrestrial Environment Laboratory, Nagoya University for construction of $210 \mathrm{MM}$ database and CPMN project of Kyushu University for providing the Tixie data; the ACE MAG instrument team, N. Ness at the Bartol Research Institute and CDAWeb for providing the ACE MAG data; and M. G. Henderson for providing LANL data. During this study J. A. Wild, G. Provan and A. Grocott were supported by PPARC grant PPA/G/O/2001/00014. S. E. Milan was supported by PPARC grant number PPA/N/2000/00197. S. W. H. Cowley was supported by PPARC Senior Fellowship grant PPA/N/S/2000/00197. N. C. Draper was funded by a University of Leicester postgraduate studentship. M. Lester was partly supported by the Institute of Advanced Study, La Trobe University during the preparation of this manuscript.

Topical Editor T. Pulkkinen thanks T. S. Hsu and another referee for their help in evaluating this paper.

\section{References}

Akasofu, S.-I.: The development of the auroral substorm, Planet. Space Sci., 12, 273-282, 1964.

Baker, D. N., Pulkkinen, T. I., Angelopoulos, V., Baumjohann, W., and McPherron, R. L.: Neutral line model of substorms: Past results and present viewJ. Geophys. Res., 101, 12 975-13010, 1996.

Balogh, A., Dunlop, M. W., Cowley, S. W. H., Southwood, D. J., Thomlinson, J. G., Glassmeier, K.-H., Musmann, G., Lühr, H., Buchert, S., Acuña, M. H., Fairfield, D. H., Slavin, J. A., Riedler, W., Shwingenschuh, K., and Kivelson, M. G.: The Cluster magnetic fields investigation Space Sci. Rev., 79, 65-91, 1997.

Blake, J. B., Fennell, J. F., Friesen, L. M., Johnson, B. M., Kolasinski, W. A., Mabry, D. J., Osborn, J. V., Penzin, S. H., Schnauss, E. R., Spence, H. E., Baker, D. N., Belian, R., Fritz, T. A., Ford, W., Laubscher, B., Stiglich, R., Baraze, R. A., Hilsenrath, M. F., Imhof, W. L., Kilner, J. R., Mobilia, J., Voss, H. D., Korth, A., Gull, M., Fischer, K., Grande, M., and Hall, D., CEPPAD: Comprehensive Energetic Particle and Pitch Angle Distribution Experiment on POLAR Space Sci. Rev., 71, 531, 1995.

Chao, J. K., Kan, J. R., Lui, A. T. Y., and Akasofu, S. I.: A model for thinning of the plasma sheet, Planet. Space Sci., 25 (8), 703 $710,1977$.

Dewhurst, J. P., Owen, C. J., Fazakerley, A. N., and Balogh, A.: Thinning and Expansion of the Substorm Plasma Sheet: Cluster PEACE Timing Analysis, Ann. Geophys., in press, 2004.

Draper, N. C., Lester, M., Cowley, S. W. H., Bosqued, J.-M., Grocott, A., Wild, J. A., Bogdanova, Y., Fazakerley, A. N., and Davies, J. A.: Cluster observations of a magnetic field cavity in the plasma sheet, Adv. Space Res., in press, 2004.

Eastman, T. E., Frank, L. A., Peterson, W. K., and Lennartsson, W.: The plasma sheet boundary layer, J. Geophys. Res., 89, 15531572, 1984.

Escoubet, C. P., Russel, C. T., and Schmidt, R.: The Cluster and Phoenix Missions. Space Science Reviews, 79, 1997.

Greenwald, R. A., Baker, K. B., Dudeny, J. R., Pinnock, M., Jones, T. B., Thomas, E. C., Villain, J.-P., Cerisier, J.-C., Senior, C., Hanuise, C., Hunsucker, R. D., Sofko, G., Koehler, J., Nielsen, E., Pellinen, R., Walker, A. D. M., Sato, N., and Yamagishi, H.: Darn/SuperDARN: a global view of the dynamics of highlatitude convectionSpace Sci. Rev., 71, 761-796, 1995.

Johnstone, A. D., Alsop, C., Burge, S., Carter, P. J., Coates, A. J., Coker, A. J., Fazakerley, A. N., Grande, M., Gowen, R. A., Gurgiolo, C., Hancock, B. K., Narheim, B., Preece, A., Sheather, P. H., Winningham, J. D., and Woodliffe, R. D.: Peace: A Plasma 
Electron and Current ExperimentSpace Sci. Rev. 79, 351-398, 1997.

Khan, H. and Cowley, S. W. H.: Observations of the response time of high-latitude ionospheric convection to variations in the interplanetary magnetic field using EISCAT and IMP-8 data Ann. Geophys., 17, 1306, 1999.

Lester, M., Hughes, W. J., and Singer, H. J.: Polarization patterns of Pi2 magnetic pulsations and the substorm current wedge J. Geophys. Res., 88, 7958-7966, 1983.

Lui, A. T. Y.: Current disruption in the Earth's magnetosphere: Observations and models J. Geophys. Res., 101, 13 067-13 088, 1996.

Lyons, L. R., Nagai, T., Blanchard, G. T., Samson, J. C., Yamamoto, T., Mukai, T., Nishida, A., and Kokubun, S.: Association between geotail plasma flows and auroral poleward boundary intensifications observed by CANOPUS photometers, J. Geophys. Res., 104, 4485, 1999.

McComas, D. J., Bame, S. J., Barker, P., Feldman, W. C., Phillips, J. L., Riley, P., and Griffee, J. W.: Solar wind electron proton alpha monitor (SWEPAM) for the Advanced Composition Explorer Space Sci. Rev., 86, 563, 1998.

McPherron, R. L.: Growth phase of magnetospheric substorms, J. Geophys. Res., 75, 5592, 1970.

McPherron, R. L., Russell, C. T., and Aubry, M. P.: Satellite studies of magnetospheric substorms on 15 August 1968, 9, Phenomenological model for substorms J. Geophys. Res., 78, 3131-3149, 1973.

Nagai, T., Fujimoto, M., Saito, Y., Machida, S., Terasawa, T., Nakamura, R., Yamamoto, T., Mukai, T., Nishida, A., and Kokubun, S.: Structure and dynamics of magnetic reconnection for substorm onsets with Geotail observations, J. Geophys. Res., 103, 4419-4440, 1998.

Nakamura, R., Amm, O., Laakso, H., Draper, N., Lester, M., Grocott, A., Klecker, B., McCrea, I. W., Balogh, A., Rème, H., and André, M.: Localized fast flow disturbance observed in the plasma sheet and in the ionosphere, Ann. Geophys., accepted, 2004.

Rème, H., Bosqued, J. M., Sauvaud, J. A., Cros, A., Dandouras, J., Aoustin, C., Bouyssou, J., Camus, Th., Cuvilo, J., Martz, C., Médale, J. L., Perrier, H., Romefort, D., Rouzaud, J., d'Uston, D., Möbius, E., Crocker, K., Granoff, M., Kistler, L. M., Popecki, M., Hovestadt, D., Klecker, B., Paschmann, G., Scholer, M., Carlson, C. W., Curtis, D. W., Lin, R. P., McFadden, J. P., Formisano, V., Amata, E., Bavassano- Cattaneo, M. B., Baldetti, P., Belluci, G., Bruno, R., Chionchio, G., di Lellis, A., Shelley, E. G., Ghielmetti, A. G., Lennartsson, W., Korth, A., Rosenbauer, U., Lundin, R., Olsen, S., Parks, G. K., McCarthy, M., and Balsiger, H.: The Cluster Ion Spectrometry (CIS) Experiment Space Sci. Rev. 79, 303-350, 1997.
Riedler, W., Torkar, K., Rüdenauer, F., Fehringer, M., Pedersen, A., Schmidt, R., Grard, R. J. L., Arends, H., Narheim, B. T., Troim, J., Torbert, R., Olsen, R. C., Whipple, E., Goldstein, R., Valavanoglou, N., Zhao, H.: Active Spacecraft Potential Control. Sp. Sc. Rev., 79, 271-302, 1997.

Rostoker, G., Akasofu, S.-I., Foster, J., Greenwald, R. A., Lui, A. T. Y., Kamide, Y., Kawasaki, K., McPherron, R. L., and Russell, C. T.: Magnetospheric substorms - Definition and signatures, J. Geophys. Res., 85, 1663-1668, 1980.

Ruohoniemi, J. M. and Baker, K. B.: Large-scale imaging of highlatitude convection with Super Dual Auroral Radar Network HF radar observations, J. Geophys. Res., 103, $20797,1998$.

Sandholt, P. E., Farrugia, C. J., Lester, M., Cowley, S., Milan, S., Denig, W. F., Lybekk, B., Trondsen, E., and Vorobjev, V.: Multistage substorm expansion: Auroral dynamics in relation to plasma sheet particle injection, precipitation, and plasma convection, J. Geophys. Res., 107, 1342, doi:10.1029/2001JA900116, 2002.

Shiokawa, K., Baumjohann, W., Haerendel, G., Paschmann, G., Fennel, J. F., Friis-Christensen, E., Luhr, H., Reeves, G. D., Russell, C. T., Sutcliffe, P. R., and Takahashi, K.: High-speed ion flow, substorm current wedge, and multiple Pi2 pulsations, J. Geophys. Res., 103, 4491-4507, 1998.

Smith, C. W., Acuña, M. H., Burlaga, M. F., L'Heureux, J., Ness, N. F., and Scheifele, J.: The ACE Magnetic Fields Experiment Space Science Review, 86, 613-632, 1998.

Stone, E. C., Frandsen, A. M., Mewaldt, R. A., Christian, E. R., Margolies, D., Ormes, J. F., and Snow, F.: The Advanced Composition Explorer Space Sci. Rev., 86, 1-22, 1998.

Tsyganenko, N. A. and Stern, D. P.: Modeling the global magnetic field of the large-scale Birkeland current systems, J. Geophys. Res., 101, 27 187-27 198, 1996.

Viljanen, A. and Häkkinen, L.: IMAGE magnetometer network. In: Satellite-Ground Based Coordination Sourcebook (eds. M. Lockwood, M. N. Wild and H. J. Opgenoorth) ESA publications SP-1198, 111-117, 1997.

Wilken, B., Axford, W. I., Daglis, I., Daly, P., Güttler, W., Ip, W. H., Korth, A., Kremser, G., Livi, S., Vasyliunas, V. M., Woch, J., Baker, D., Belian, R. D., Blake, J. B., Fennell, J. F., Lyons, L. R., Borg, H., Fritz, T. A., Gliem, F., Rathje, R., Grande, M., Hall, D., Kecsueméty, K., McKenna-Lawlor, S., Mursula, K., Tanskanen, P., Pu, Z., Sandahl, I., Sarris, E. T., Scholer, M., Schulz, M., Sørass, F., and Ullaland, S.: RAPID. The Imaging Energetic Particle Spectrometer on ClusterSpace Sci. Rev. 79, 399-473, 1997. 